\title{
Erratum to: Diagnosis of tetrahydrobiopterin deficiency using filter paper blood spots: further development of the method and 5 years experience
}

Thomas Opladen • Bettina Abu Seda • Anahita Rassi • Beat Thöny • Georg F. Hoffmann • Nenad Blau

Published online: 31 May 2011

(C) SSIEM and Springer 2011

Erratum to: J Inherit Metab Dis

DOI 10.1007/s10545-011-9300-1

In the original published article units for hemoglobin concentrations in blood are erroneously reported as $\mathbf{g} / \mathbf{d L}$ instead as $\mathbf{g} / \mathbf{L}$. However, all neopterin and biopterin values reported in the text and tables are correct and calculated with $\mathrm{Hb} \mathrm{g} / \mathrm{L}$.

We apologize for any inconvenience caused by this mistake.

The Authors

The online version of the original article can be found at http://dx.doi. org/10.1007/s10545-011-9300-1.

T. Opladen · G. F. Hoffmann

Division of Inborn Metabolic Diseases,

University Children's Hospital Heidelberg,

Heidelberg, Germany

B. Abu Seda $\cdot$ A. Rassi $\cdot$ B. Thöny $\cdot$ N. Blau $(\bowtie)$

Division of Clinical Chemistry and Biochemistry,

University Children's Hospital Zürich,

Zürich, Switzerland

e-mail: nenad.blau@kispi.unizh.ch

B. Thöny $\cdot$ N. Blau

Zürich Center for Integrative Human Physiology (ZIHP),

Steinwiesstrasse 75 ,

8032 Zürich, Switzerland

B. Thöny $\cdot$ N. Blau

Research Center for Children (RCC),

Zürich, Switzerland 